\title{
Maghemite nanoparticles coated by methacrylamide-based polymer for magnetic particle imaging
}

\author{
Vít Herynek (1D) - Michal Babič • Ondřej Kaman • Hana Charvátová • Mariana Veselá • \\ Oliver Buchholz • Magda Vosmanská • Denisa Kubániová • Jaroslav Kohout • Ulrich G. \\ Hofmann • Luděk Šefc
}

Received: 27 October 2020 / Accepted: 9 February 2021/Published online: 18 February 2021

(C) The Author(s) 2021

\begin{abstract}
A wise selection of tracers is critical for magnetic particle imaging (MPI). Most of the current tracers are based on superparamagnetic iron oxide nanoparticles (SPIONs) with a suitable coating. We prepared maghemite cores $\left(\gamma-\mathrm{Fe}_{2} \mathrm{O}_{3}\right)$ by coprecipitation of $\mathrm{Fe}(\mathrm{II})$ and $\mathrm{Fe}$ (III) salts with ammonium hydroxide followed by oxidation with hydrogen peroxide and stabilization as an anionic $\left(\gamma-\mathrm{Fe}_{2} \mathrm{O}_{3}{ }^{\ominus}\right)$ or cationic colloid $\left(\gamma-\mathrm{Fe}_{2} \mathrm{O}_{3}{ }^{\oplus}\right)$. The cores were coated by $\operatorname{poly}(N-(2-$
\end{abstract}

The results were presented, in part, at the $10^{\text {th }}$ International Workshop on Magnetic Particle Imaging, September 7-9, 2020, as a poster presentation with interim findings. The abstract of the presentation was published in International Journal on Magnetic Particle Imaging, 6(2), Suppl 1, Article ID 2009019, DOI: 10.18416/IJMPI.2020.2009019. The actual paper, however, has never been published.

V. Herynek $(\bowtie) \cdot$ M. Veselá $\cdot$ L. Šefc

First Faculty of Medicine, Center for Advanced Preclinical Imaging, Charles University, Salmovská 3, 12000 Prague, Czech Republic

e-mail: vit.herynek@1f1.cuni.cz

M. Babič $\cdot$ H. Charvátová

Institute of Macromolecular Chemistry, Czech Academy of

Science, Prague, Czech Republic

O. Kaman

Institute of Physics, Czech Academy of Science, Prague,

Czech Republic

O. Buchholz • U. G. Hofmann

Section for Neuroelectronic Systems, Department of

Neurosurgery, Medical Center - University of Freiburg, Freiburg, hydroxypropy l) methacrylamide)-co$\mathrm{N}$-[2-(hydroxyamino)-2-oxo-ethyl]-2-methyl-prop-2enamide. The particles were characterized by dynamic light scattering, transmission electron microscopy, Xray diffraction, Mössbauer spectroscopy, tested in vitro in a field-free point MPI scanner, and compared to nanoparticles prepared by oxidation with sodium hypochlorite and to the commercially available Resovist ${ }^{\circledR}$. The cores had an average diameter of $8.0 \mathrm{~nm}(\gamma-$

Germany

O. Buchholz • U. G. Hofmann

Faculty of Medicine, University of Freiburg, Freiburg, Germany

M. Vosmanská

Department of Analytical Chemistry, University of Chemistry and Technology, Prague, Czech Republic

D. Kubániová · J. Kohout

Faculty of Mathematics and Physics, Department of Low

Temperature Physics, Charles University, Prague,

Czech Republic 
$\left.\mathrm{Fe}_{2} \mathrm{O}_{3}{ }^{\oplus}\right)$ and $8.7 \mathrm{~nm}\left(\gamma-\mathrm{Fe}_{2} \mathrm{O}_{3}{ }^{\ominus}\right)$; the hydrodynamic diameter was $88 \mathrm{~nm}$. Zeta potential values for both positively charged $(+52 \mathrm{mV})$ and negatively charged particles $(-60 \mathrm{mV})$ provided for good colloidal stabilization. Spinel structure of maghemite was confirmed by Mössbauer spectroscopy. The uncoated $\gamma-\mathrm{Fe}_{2} \mathrm{O}_{3}{ }^{\oplus}$ particles yielded an MPI signal lower (by $16 \%$ ) than Resovist; the coated ones reached $88 \%$ of the Resovist signal. Anionic $\gamma-\mathrm{Fe}_{2} \mathrm{O}_{3}{ }^{\ominus}$ particles reached a higher (uncoated particles, by $15 \%$ ) or comparable (coated ones) signal relative to Resovist with a substantially lower signal dispersion. Control particles prepared by oxidation with sodium hypochlorite scored the weakest results. To conclude, a suitable size, narrow size distribution, and colloidal stability predispose the synthetized particles for use as a tracer for MPI. The anionic particles provided a higher signal with a lower dispersion than commercial tracers.

Keywords Maghemite nanoparticles ·

Superparamagnetic iron oxide - Magnetic particle imaging $\cdot$ Magnetometry $\cdot$ Mössbauer spectroscopy

\section{Introduction}

Magnetic particle imaging (MPI) is a recent noninvasive imaging technique taking its rightful place among well-established alternatives, such as magnetic resonance imaging or computer tomography. It is based on the response of magnetic nanoparticles to a varying magnetic field. This novel imaging technique was introduced by Gleich et al. (Gleich and Weizenecker 2005) in 2005. The method requires suitable magnetic tracers. As it enables detection of just the tracer, it provides no anatomical information and needs to be combined with another imaging technique, preferably MR or CT.

The method may achieve a high spatial and temporal resolution; however, it strongly depends on the technical properties of the actual MPI scanner as well as on the tracers used.

Most tracers are based on superparamagnetic iron oxide nanoparticles (SPIONs), mainly magnetite $\left(\mathrm{Fe}_{3} \mathrm{O}_{4}\right)$ and maghemite $\left(\gamma-\mathrm{Fe}_{2} \mathrm{O}_{3}\right)$ (Bulte 2019). SPIONs are extensively studied, as they may be used in a number of biomedical applications (Vallabani and Singh 2018).
As iron oxide may be potentially toxic (Novotna et al. 2012), the particles need a suitable coating to ensure water dispersibility along with safety and stability, and potentially even to allow further surface modifications (Zhu et al. 2018). Various materials have been studied as SPION surface coating options. Carboxydextran was used in ferucarbotran (Reimer and Balzer 2003), an MR contrast agent commercially available in the past. Dextran (Kawaguchi et al. 2001), polyethylene glycol (Zhang and Zhang 2005), chitosan (Lopez et al. 2013), D-mannose (Horak et al. 2007), poly(L-lysine) (Babic et al. 2008), or poly( $N, N$ dimethylacrylamide) (Babic et al. 2009) are also common coatings. The coating itself (or in combination with transfection agents) can facilitate endocytosis, when nanoparticles are used for cell labelling (Horak et al. 2007; Babic et al. 2008; Arbab et al. 2003; Kalish et al. 2003).

MPI is extremely sensitive to the particles' magnetic moment, superparamagnetic behavior at scanning frequencies, and particle mobility in the solvent. Therefore, the applicability of magnetic particles in MPI is closely linked to the structure of magnetic cores, core size, and particle coating. According to the Langevin theory, the resolution of the MPI (Goodwill and Conolly 2010; Weizenecker et al. 2007) should improve significantly with an increasing SPION diameter. However, increasing the nanoparticle size also affects the relaxation mechanisms, which may result in signal reduction due to a phase lag at working frequencies (Ferguson et al. 2009) or limitations in the drive field (Croft et al. 2016).

In this study, we prepared iron oxide nanoparticles by using a modified protocol; the particles were then coated by polar derivatives of poly( $N-(2-$ hydroxypropyl)methacrylamide) (HPMA)-based polymer. Linear poly(HPMA) was chosen as a particle coating because of its bioinert properties and its ability to form a sterically stabilizing coating. HPMA was previously used for the biocompatible coating of viral capsids, nucleic acid, or latexes, as well as soluble drug delivery systems (Laga et al. 2007, 2012; Subr et al. 2006). Copolymerization of HPMA with $N$-[2-(hydroxyamino)-2-oxo-ethyl]-2-methyl-prop-2-enamide (HAO) introduced into the neutral polymer chain very strongly chelating groups with $\mathrm{Fe}^{3+}$. The particles were characterized by transmission electron microscopy (TEM), dynamic light scattering (DLS), Mössbauer spectroscopy, and magnetometry and in vitro tested using a simplified MPI measurement protocol. 


\section{Materials and methods}

Preparation of maghemite nanoparticles

Aqueous solutions were prepared by dissolving $\mathrm{FeCl}_{3} \cdot 6 \mathrm{H}_{2} \mathrm{O}$ and $\mathrm{FeCl}_{2} \cdot 4 \mathrm{H}_{2} \mathrm{O}$ (Sigma-Aldrich, Prague, Czech Republic) in water and then purified by centrifugation for $10 \mathrm{~min}$ at $4400 \mathrm{rpm}$ prior to use. The solution of $\mathrm{FeCl}_{3}(0.2 \mathrm{M}, 100 \mathrm{~mL}$, was treated with aqueous ammonia (0.5 M, $100 \mathrm{~mL}$, Sigma-Aldrich) under sonication for 2 min. Then, the $\mathrm{FeCl}_{2}$ solution $(0.2 \mathrm{M}, 55 \mathrm{~mL})$ was added. The dispersion was poured into aqueous ammonia $(0.5 \mathrm{M}$, $250 \mathrm{~mL}$ ) and stirred. Black particles presumably of magnetite nature were formed. The mixture was stirred for $1 \mathrm{~h}$ and allowed to sediment. The supernatant was discarded and the sedimented particles were purified by repeated addition of water followed by magnetic separation and decantation five times. $\mathrm{H}_{2} \mathrm{O}_{2}$ solution $(3 \%, 6 \mathrm{~mL})$ was added to the colloid and sonicated for $10 \mathrm{~min}$. The colloid was magnetically separated for 4 days, the supernatant was discarded, and the nanoparticles were redispersed in water $(20 \mathrm{~mL})$. Cationic colloid $\left(\gamma-\mathrm{Fe}_{2} \mathrm{O}_{3}{ }^{\oplus}\right)$ was obtained by addition of $\mathrm{HCl}(0.2 \mathrm{M}, 9 \mathrm{~mL}$, Lach-Ner, Neratovice, Czech Republic) under sonication for $2 \mathrm{~min}$. Anionic colloid $\left(\gamma-\mathrm{Fe}_{2} \mathrm{O}_{3}{ }^{\ominus}\right)$ was prepared by addition of trisodium citrate dihydrate solution (0.1 M, $12 \mathrm{~mL}$, Sigma-Aldrich) before oxidation with $\mathrm{H}_{2} \mathrm{O}_{2}$. Consequently, the colloids were repeatedly washed with ultrapure water $(18.2 \mathrm{M} \Omega$ ) via magnetic separation until achieving a spontaneous peptization (approx. 15-20 cycles). The last discarded supernatant had neutral $\mathrm{pH}$ in both cases. Finally, both colloids were filtered through a $0.45-\mu \mathrm{m}$ filter and their concentration was set to $60 \mathrm{mg} / \mathrm{mL}$.

Particles prepared according to (Babic et al. 2008) by oxidation with $\mathrm{NaOCl}$, also stabilized by citrate, with zeta potential $\zeta=-55 \mathrm{mV}$ were used as a control.

The three aqueous magnetic colloids, $\gamma-\mathrm{Fe}_{2} \mathrm{O}_{3}{ }^{\oplus}, \gamma$ $\mathrm{Fe}_{2} \mathrm{O}_{3}{ }^{\ominus}$, and the control $((0.5 \mathrm{~mL}, 8.8 \mathrm{mg} / \mathrm{mL})$, were coated by an aqueous solution $(0.5 \mathrm{~mL} ; 4.4 \mathrm{mg} / \mathrm{ml})$ of poly( $N$-(2-hydroxypropyl)methacrylamide)-co$\mathrm{N}$-[2-(hydroxyamino)-2-oxo-ethyl]-2-methyl-prop-2enamide (poly(HPMA-co-HAO)) under sonication. Poly(HPMA-co-HAO) with molecular weight $M_{\mathrm{n}}=$ $3.23 \cdot 10^{4}$ was synthesized via RAFT copolymerization of HPMA (0.9 g) and HAO (0.1 g) and its molecular weight was measured by size exclusion chromatography with a light scattering detector. HAO was prepared via condensation of methacrylic acid and hydroxylamine and purified on silica gel with dichlormethane/methanol (5/1) eluent.
Further on, we term particles $\gamma-\mathrm{Fe}_{2} \mathrm{O}_{3}{ }^{\oplus}$ stabilized by $\mathrm{HCl}$ cationic, particles $\gamma-\mathrm{Fe}_{2} \mathrm{O}_{3}{ }^{\ominus}$ stabilized by trisodium citrate dihydrate anionic. Particles without the poly(HPMA-co-HAO) are termed "uncoated particles," while particles with the poly(HPMA-co-HAO) coating are termed "coated."

\section{Iron content analysis}

The content of iron in aqueous suspensions of the uncoated samples $\left(\gamma-\mathrm{Fe}_{2} \mathrm{O}_{3}{ }^{\oplus}, \gamma-\mathrm{Fe}_{2} \mathrm{O}_{3}{ }^{\ominus}\right.$, and the control) was determined by chemical analysis, namely by the inductively coupled plasma mass spectrometry (ICPMS). The samples were transferred by concentrated nitric acid into Teflon vessels for microwave decomposition (UniClever BMI-Z, Plasmatronics, Poland). A mixture of $3 \mathrm{~mL}$ nitric acid and $1 \mathrm{~mL}$ hydrofluoric acid (both Suprapur, Merck, Darmstadt, Germany) was used for sample decomposition. The decomposed samples were transferred to a 50-mL volumetric flask and diluted appropriately and then spiked with an internal standard solution (100Rh). Both the calibration solutions and the IS solution were prepared from solutions at a concentration of $1.000 \pm 0.002 \mathrm{~g} / \mathrm{L}$ (Merck). All solutions were prepared with distilled and demineralized water (conductivity $<0.1 \mu \mathrm{S} / \mathrm{cm}$ ) (Millipore, Bedford, MA, USA).

To avoid any complications related to the possibility of incomplete decomposition of polymer coatings and any matrix effects in the analysis of iron, the concentration of the polymer-coated nanoparticles was determined by magnetometry on the assumption that the magnetization of the magnetic cores in the three samples is unaffected by the polymer coating. Specifically, the actual content of the maghemite phase in the coated samples was calculated from the magnetic moment of precisely weighted aliquots and from the magnetization of the initial uncoated colloids, whose concentration was determined by ICP-MS.

Dynamic light scattering

The coating efficiency, colloidal stability, and hydrodynamic size of both initial and polymer-coated particles in aqueous suspension were examined by dynamic light scattering (DLS), measuring the hydrodynamic diameter $\left(D_{\mathrm{h}}\right)$, polydispersity index (PDI), and zeta potential (द) (Zetasizer Nano Series ZEN3500, Malvern, Worcestershire, UK). All values were measured for diluted aqueous particle dispersions in disposable folded DTS1070 capillary cells. 
Transmission electron microscopy

The shape, average diameter, and size distribution of both uncoated and coated particles were evaluated directly from microphotographs obtained by a transmission electron microscope (FEI-TEM, Tecnai G2 Spirit, OR, USA). The microphotographs were analyzed with the ImageJ analysis software (Schneider et al. 2012); at least 5 images from different parts of the on-grid deposited sample were evaluated by manual measurement of at least 500 particles. The number-average diameter $\left(D_{\mathrm{n}}\right)$ and dispersity $(\nexists)$ were calculated according to the following formulas:

$D_{n}=\frac{\sum n_{\mathrm{i}} D_{\mathrm{i}}}{\sum n_{\mathrm{i}}}$

$\left.\mathrm{DH}=\frac{D_{w}}{D_{n}} ;<1, \infty\right)$

where $n_{\mathrm{i}}$ is the number of the nanoparticles, $D_{\mathrm{i}}$ is the diameter of the nanoparticles, $D_{\mathrm{w}}$ is the weight-average diameter of the nanoparticles calculated as

$D_{w}=\frac{\sum_{i} n_{i} D_{i}^{4}}{\sum_{i} n_{i} D_{i}^{3}}$

The value of dispersity of a strictly monodisperse system is $\oslash=1.0$. Usually, systems with $\oslash=1.0-1.5$ can be classified as monodisperse, and systems with $Ð>$ 1.5 are usually classified as polydisperse.

\section{Magnetometry}

Magnetic properties of the samples were measured in DC fields by means of a Quantum Design MPMS XL SQUID magnetometer. For each suspension, an aliquot of $200 \mu \mathrm{L}$ was transferred onto a small piece of Teflon tape supported by a clock glass, weighed precisely, and dried carefully. The dry sample was mounted in a gelatin capsule for the magnetic measurements. Hysteresis loops were measured up to a magnetic field of $4 \mathrm{~T}$ at $300 \mathrm{~K}$ and $5 \mathrm{~K}$. After the loop at $5 \mathrm{~K}$, the temperature dependence of the remanent moment was measured during heating in zero field. Measurements of susceptibility in zero-field-cooled (ZFC) and field-cooled (FC) regimes were carried out on an already magnetized sample. Prior to the cooling in the zero field, the sample was heated to $320 \mathrm{~K}$ and a controlled quench of the solenoid was applied to remove any remnant fields in the superconducting winding. The probe field in the $\mathrm{ZFC} / \mathrm{FC}$ study was $1.6 \mathrm{kA} / \mathrm{m}$ (20 Oe).

X-ray diffraction

Aliquots of aqueous suspensions of bare anionic, cationic, and control nanoparticles were carefully dried at room temperature in vacuo, and the resulting samples were subjected to powder X-ray diffraction (XRD) to analyze the phase composition and crystal structure of the bare particles. The samples were placed on a nondiffracting monocrystalline silicon plate, and XRD patterns were collected at room temperature by a Bruker D8 Advance diffractometer with $\mathrm{Cu} \mathrm{K} \alpha$ radiation. The patterns were analyzed by the Rietveld method in the FULLPROF program.

\section{Mössbauer spectroscopy}

The transmission Mössbauer spectra of frozen aqueous suspensions of uncoated $\gamma-\mathrm{Fe}_{2} \mathrm{O}_{3}{ }^{\oplus}$ and $\gamma-\mathrm{Fe}_{2} \mathrm{O}_{3}{ }^{\ominus}$, coated $\gamma-\mathrm{Fe}_{2} \mathrm{O}_{3}{ }^{\oplus}$ and $\gamma-\mathrm{Fe}_{2} \mathrm{O}_{3}{ }^{\ominus}$ particles, uncoated control sample, and Resovist ${ }^{\circledR}$ were acquired at liquid helium temperature.

All experiments were accomplished with a conventional constant-acceleration spectrometer (WissEL, Ortenberg, Germany) equipped with a ${ }^{57}$ Co source diffused in $\mathrm{Rh}$ matrix. The spectrometer was calibrated using as a standard a $12.5-\mu \mathrm{m}$ foil of $\alpha-\mathrm{Fe}$ at room temperature. The Mössbauer spectroscopy experiments at liquid helium temperature and external magnetic field were performed in a SVT-400 bath cryostat Janis (Janis Research, Woburn, MA, USA). The direction of external magnetic field is perpendicular to $\gamma$-ray direction. The spectral parameters (relative integral intensity $I$, isomer shift $I S$, quadrupole shift/splitting $Q S$ and magnetic hyperfine/effective field $B_{\mathrm{hf}} / B_{\text {eff }}$ ) were derived by the help of the CONFIT® (Žák and Jirásková 2006) fitting software.

Magnetic particle imaging

In vitro MPI measurements were performed using a "field-free point" preclinical MPI scanner (Bruker BioSpin, Rheinstetten, Germany). The samples were measured using a fast, simplified protocol (Herynek et al. 2020), which consisted of: 
a. A low-matrix calibration (matrix $5 \times 5 \times 3$, field of view FOV $=10 \times 10 \times 6 \mathrm{~mm}^{3}, 2 \mathrm{~mm}$ isotropic resolution, $\mathrm{DF}=14 \mathrm{mT}, \mathrm{SF}=2 \mathrm{~T} / \mathrm{m}$, no. of acquisitions $\mathrm{NA}=128$, frequency range $90-625 \mathrm{kHz}$ ) performed with a nanoparticle sample $8 \mu \mathrm{L}$, i.e., a cube $2 \times 2 \times 2$ $\mathrm{mm}^{3}$ exactly matching the voxel size. The concentration was set to $2.5 \mathrm{mg} \mathrm{Fe} / \mathrm{mL}$. There were two calibration measurements performed; i.e., two system matrices were acquired for each sample.

b. Three scans (with the same settings) of the same sample in seven different positions within the FOV. Each measurement was evaluated with both system matrices producing 6 images for each position.

Two image parameters were evaluated: signal-tonoise ratio (a signal from the voxel containing the sample tube divided by the average signal from all other voxels, further on $\mathrm{S} / \mathrm{N}$ ) and signal displacement (maximum signal outside the sample area divided by the signal in the voxel with the test tube). The parameters were evaluated by an in-house script ISNER (Matlab, MathWorks, Natick, MA, USA). The average values from the three measurements/two evaluations/seven positions are presented below.

The same procedure was applied to Resovist ${ }^{\circledR}$ for a comparison. The signal-to-noise ratio was related to Resovist $(=100 \%)$, which is considered a standard among MPI contrast agents.

\section{Results}

The TEM images showed a spherical shape and confirmed a narrow size distribution of both uncoated and coated particles (Fig. 1). The uncoated particles had an average diameter of $D_{\mathrm{n}}=8.0 \mathrm{~nm}$ with $Ð=1.3(\gamma$ $\left.\mathrm{Fe}_{2} \mathrm{O}_{3}{ }^{\oplus}\right)$ or $D_{\mathrm{n}}=8.7 \mathrm{~nm}$ with $\doteq=1.3\left(\gamma-\mathrm{Fe}_{2} \mathrm{O}_{3}{ }^{\ominus}\right)$. These values slightly exceeded the core size of the control sample (differently oxidized nanoparticles, $D_{\mathrm{n}}$ $=6.6 \mathrm{~nm}$ with $Ð=1.3$ (Horak et al. 2007)), or Resovist (4.2 nm (Yang et al. 2011)).

The hydrodynamic diameter of uncoated $\gamma-\mathrm{Fe}_{2} \mathrm{O}_{3}{ }^{\oplus}$ and $\gamma-\mathrm{Fe}_{2} \mathrm{O}_{3}{ }^{\ominus}$ colloid samples in water was characterized by a Z-average value of $96.9 \pm 0.9 \mathrm{~nm}$ with $\mathrm{PI}=$ $0.153 \pm 0.001$ and $96 \pm 1 \mathrm{~nm}$ with PI $=0.17 \pm 0.02$ respectively. The control particles showed a larger diameter $(143 \pm 1 \mathrm{~nm}$ with PI $=0.18 \pm 0.03)$, while Resovist is smaller (62 $\mathrm{nm}$ according to (Reimer and Balzer 2003), or 45-60 nm according to (Wang 2011)).
The uncoated positively charged particles had in ultrapure water a potential of $\zeta=+41 \pm 1 \mathrm{mV}(\mathrm{pH}=$ 5 ), while the negatively charged ones showed $\zeta=-52 \pm$ $1 \mathrm{mV}(\mathrm{pH}=8)$. Washed colloids still showed some acidobasic activity, although the last discarded washing supernatant had neutral $\mathrm{pH}$ in both cases. This behavior can be explained by a proteolytic activity of ions complexed (citrate) or present $\left(\mathrm{Fe}^{3+}\right)$ on the particle surface (Spitzer 1992, 2003a, b; Spitzer et al. 1989).

The particles coated by poly(HPMA-co-HAO) revealed a hydrodynamic diameter of $118 \pm 2 \mathrm{~nm}$ with $\mathrm{PI}=0.141 \pm$ $0.009\left(\gamma-\mathrm{Fe}_{2} \mathrm{O}_{3}{ }^{\oplus}\right)$ or $109.1 \pm 0.1 \mathrm{~nm}$ with $\mathrm{PI}=0.12 \pm 0.01$ $\left(\gamma-\mathrm{Fe}_{2} \mathrm{O}_{3}{ }^{\ominus}\right)$, similar to the poly(HPMA-co-HAO) coated control particles $(117 \pm 1 \mathrm{~nm}$ with $\mathrm{PI}=0.13 \pm 0.02)$. Zeta potentials of poly(HPMA-co-HAO) coated particles were $\zeta=23.2 \pm 0.2 \mathrm{mV}(\mathrm{pH}=5)\left(\gamma-\mathrm{Fe}_{2} \mathrm{O}_{3}{ }^{\oplus}\right)$ and $\zeta=-28.5 \pm$ $0.5 \mathrm{mV}(\mathrm{pH}=7.6)\left(\mathrm{Fe}_{2} \mathrm{O}_{3}{ }^{\ominus}\right)$ in ultrapure water. Hydrodynamic properties of the particles were measured also in physiological PBS buffer $(\mathrm{pH}=7.4$ ) to prove their potential applicability in biological systems. Values for uncoated particles were $D_{\mathrm{h}}=4100 \pm 400 \mathrm{~nm}, \mathrm{PI}=0.3 \pm 0.2$, and $\zeta=$ $-25 \pm 2$ for $\gamma-\mathrm{Fe}_{2} \mathrm{O}_{3}{ }^{\oplus}$ and $D_{\mathrm{h}}=2000 \pm 200 \mathrm{~nm}, \mathrm{PI}=0.3 \pm$ 0.1 and $\zeta=-26.3 \pm 0.7$ for $\mathrm{Fe}_{2} \mathrm{O}_{3}{ }^{\ominus}$. Data for poly(HPMAco-HAO) coated particles were poly(HPMA-co-HAO) $D_{\mathrm{h}}$ $=114.1 \pm 0.7 \mathrm{~nm}, \mathrm{PI}=0.131 \pm 0.007$, and $\zeta=-5 \pm 0.5$ for $\gamma-\mathrm{Fe}_{2} \mathrm{O}_{3}{ }^{\oplus}$ and $D_{\mathrm{h}}=109.3 \pm 0.6 \mathrm{~nm}, \mathrm{PI}=0.115 \pm 0.008$, and $\zeta=-4.2 \pm 0.9$ for $\mathrm{Fe}_{2} \mathrm{O}_{3}{ }^{\ominus}$.

Graphs of size distribution of uncoated and poly(HPMA-co-HAO) coated cationic $\gamma-\mathrm{Fe}_{2} \mathrm{O}_{3}{ }^{\oplus}$ and anionic $\mathrm{Fe}_{2} \mathrm{O}_{3}{ }^{\ominus}$ particles are shown in Supplementary Information (Fig. S1a, b).

The DLS data confirmed a stabilizing role of the coating polymer, which is supported namely by a PI decrease when compared to the PDI of uncoated particles in water. Values of Zeta potentials of the coated particles decreased (in absolute values) in comparison with values of uncoated particles. This effect can be ascribed to a strong complexation activity of the hydroxamate group, which compensate the original charge by the creation of a chelate on maghemite particles surface. Moreover, the decrease of the Zeta potential is not followed by the loss of colloidal stability, what confirms the steric stabilization effect of the polymer coating. This observation was undoubtedly confirmed with DLS measurement in PBS buffer, where coated particles showed resistance against precipitation by salts (especially by iron complexing phosphate anions) as contrasted to uncoated ones. 


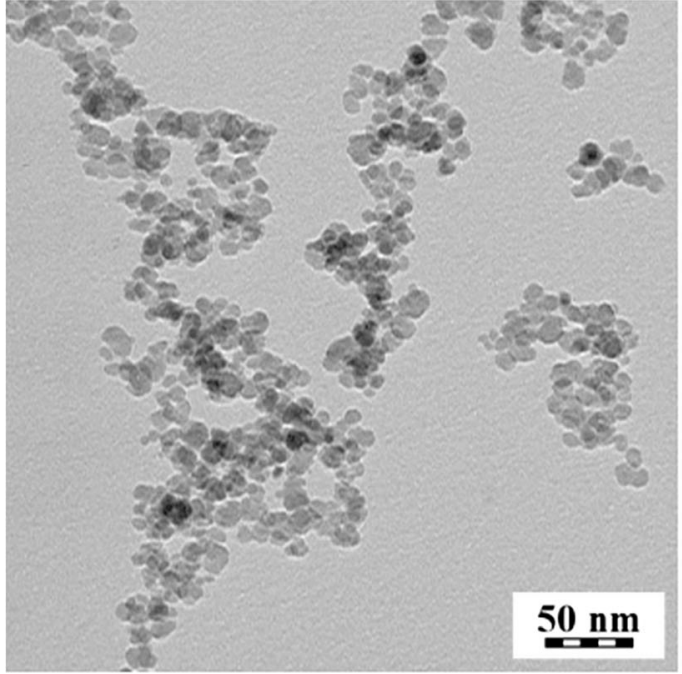

a

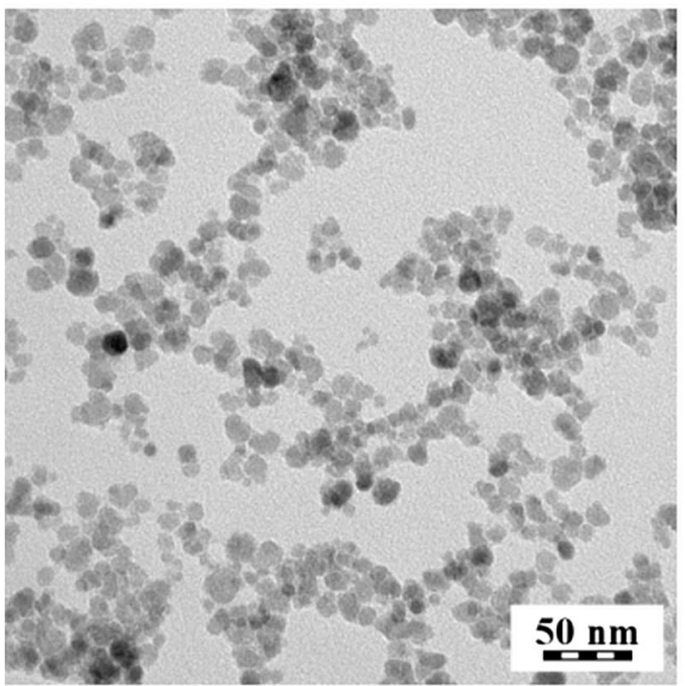

C

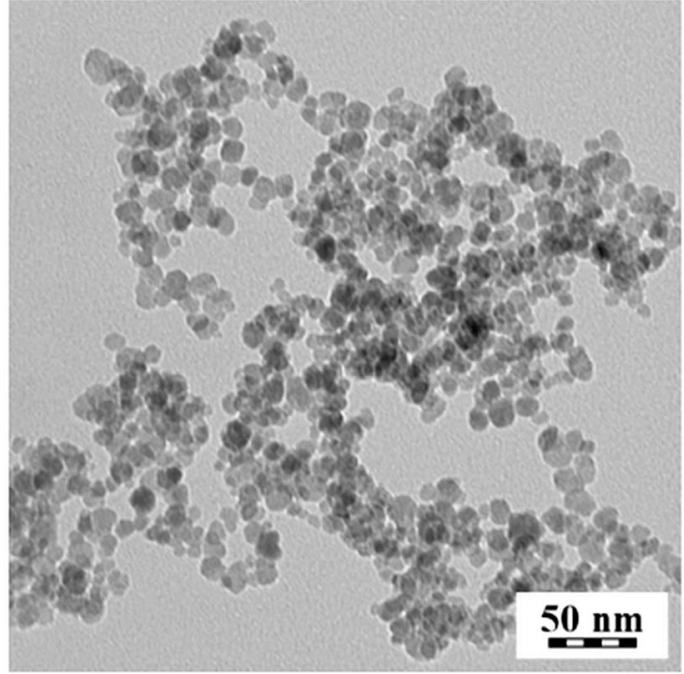

b

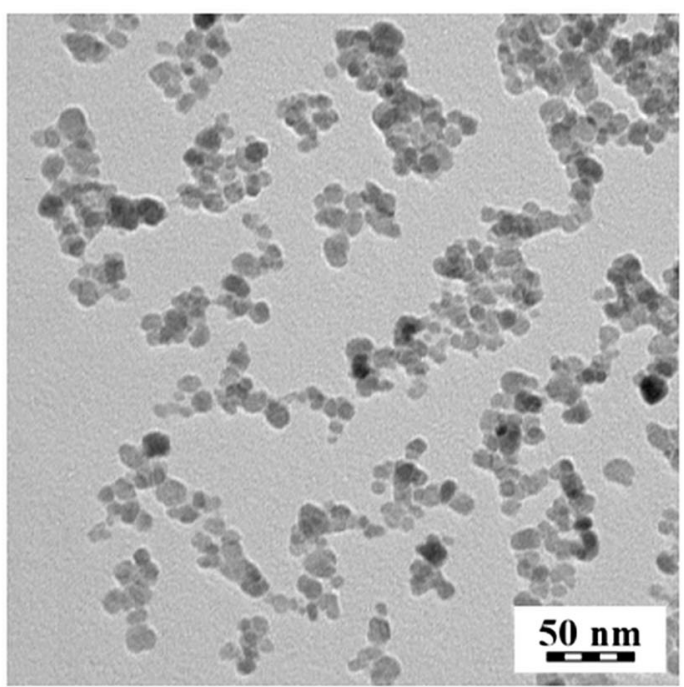

d

Fig. 1 Transmission electron microscopy images of the uncoated cationic $\gamma-\mathrm{Fe}_{2} \mathrm{O}_{3}{ }^{\oplus}$ (a), uncoated anionic $\gamma-\mathrm{Fe}_{2} \mathrm{O}_{3}{ }^{\ominus}$ (b), poly(HPMA-coHAO)-coated cationic $\gamma$ - $\mathrm{Fe}_{2} \mathrm{O}_{3}{ }^{\oplus}(\mathbf{c})$, and poly(HPMA-co-HAO)-coated anionic $\gamma$ - $\mathrm{Fe}_{2} \mathrm{O}_{3}{ }^{\ominus}$ nanoparticles (d)

\section{Magnetometry}

Magnetization curves of the initial uncoated particles are shown in Fig. 2. Although hysteresis is observed at $5 \mathrm{~K}$ (Fig. 2a), the samples revealed anhysteretic curves at room temperature with coercivity below the experimental limit of the measurement (Fig. 2b). With Resovist, a gradual increase of susceptibility indicated a broad distribution of core sizes. Specific magnetization of cores in the magnetic field of $3 \mathrm{~T}$ at $300 \mathrm{~K}$ is summarized in
Table 1. The temperature dependence of remanent magnetization is also depicted for both the initial and polymer-coated nanoparticles in Fig. 3.

The ZFC/FC study (Fig. 4a) confirmed the ferromagnetic behavior of anionic, cationic, and control particles (both uncoated and coated ones). The susceptibility decrease (in both ZFC and FC regimes) at higher temperature (cationic $\gamma-\mathrm{Fe}_{2} \mathrm{O}_{3}{ }^{\oplus}$ ) corresponds to loss of magnetization due to thermal movement. 
Fig. 2 Hysteresis loops of the uncoated magnetic nanoparticles at $5 \mathrm{~K}$ (a) and room temperatures (b). The insets show low-field details of the loops in the range of $\mu_{0} H=-250-250 \mathrm{mT}$
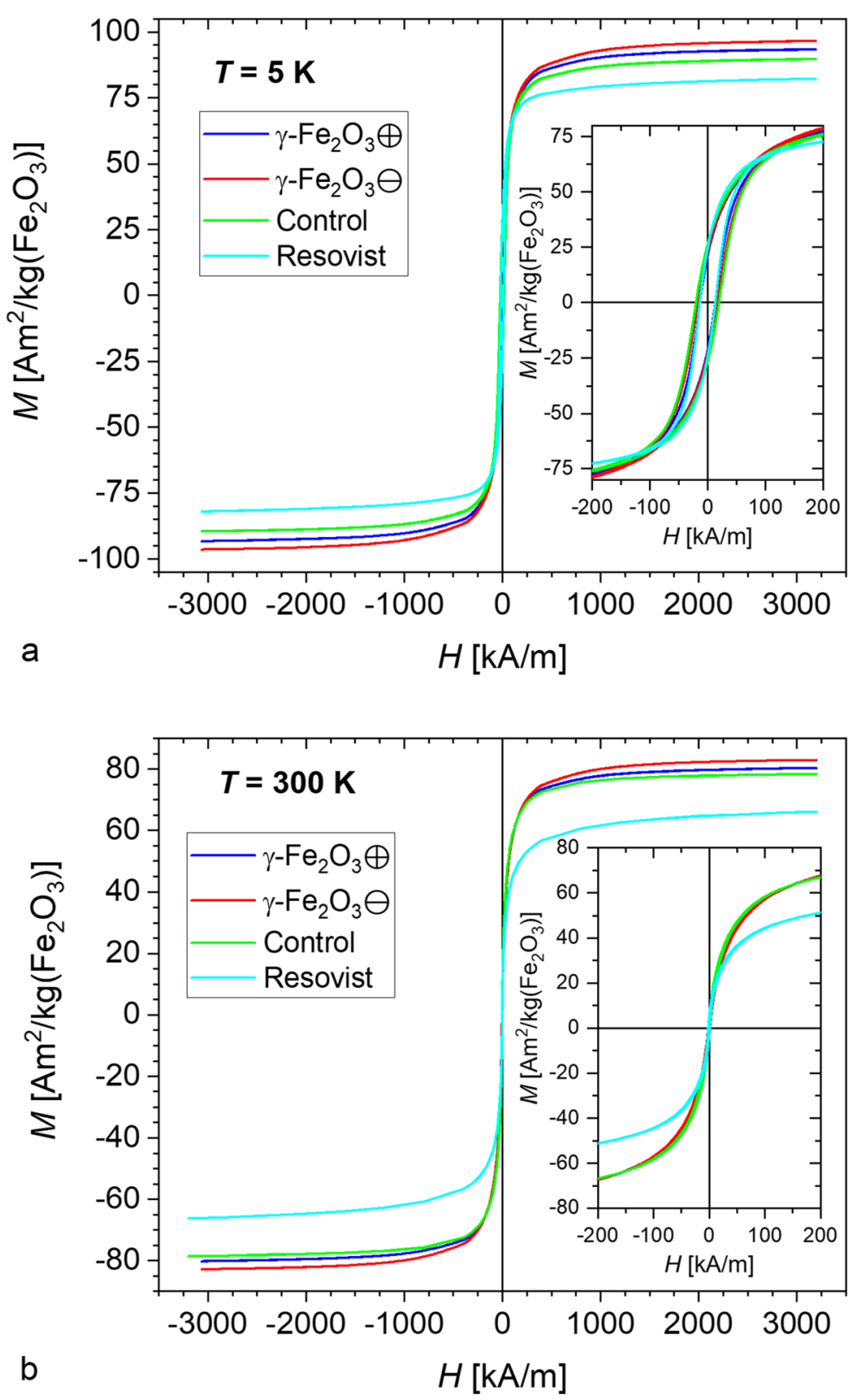

The rather linear increase of susceptibility in the ZFC regime (and the constant behavior of control particles (uncoated as well as coated) in the FC regime indicated a substantial paramagnetic component.

Similarly, an increase of susceptibility of Resovist in the FC regime confirmed a broader distribution of core sizes.

A convergence of the ZFC and FC curves of both anionic and cationic particles indicated superparamagnetic behavior at room temperature.

The temperature derivative $\left(\chi_{\mathrm{FC}}-\chi_{\mathrm{ZFC}}\right) / \mathrm{dT}$ (Fig. $\left.4 \mathrm{~b}\right)$ shows the distribution of blocking temperature in the samples. Both anionic and cationic particles revealed a sharper distribution at low temperatures corresponding to faster Néel relaxation, whereas the flat curve of the control sample indicates a broad distribution and slow Néel relaxation.

X-ray diffraction

The XRD analysis of the three uncoated samples indicated the single-phase nature and spinel structure of prepared particles. The patterns obtained, shown in Fig. 5, were 
Table 1 Hydrodynamic diameter (d), polydispersity index (PDI), and saturation magnetization at room temperature of the tested nanoparticles, both uncoated and coated by poly(HPMA-co-HAO)

\begin{tabular}{|c|c|c|c|}
\hline Particle & $\mathrm{d}(\mathrm{nm})$ & PDI & $\mathrm{M}_{\mathrm{s}}\left(\mathrm{Am} 2 / \mathrm{kg}\left(\mathrm{Fe}_{2} \mathrm{O}_{3}\right)\right)$ \\
\hline$\gamma-\mathrm{Fe} 2 \mathrm{O} 3^{\oplus}$ & $86.2 \pm 1.4$ & $0.205 \pm 0.011$ & 79.9 \\
\hline$\gamma-\mathrm{Fe} 2 \mathrm{O} 3^{\ominus}$ & $96.3 \pm 0.6$ & $0.178 \pm 0.019$ & 82.5 \\
\hline control & $142.7 \pm 5.8$ & $0.389 \pm 0.015$ & 78.1 \\
\hline$\gamma$-Fe2O3 ${ }^{\oplus}$ poly(HPMA-co-HAO) & $119.1 \pm 0.8$ & $0.145 \pm 0.037$ & - \\
\hline$\gamma$-Fe2O3 ${ }^{\ominus}$ poly(HPMA-co-HAO) & $116.4 \pm 0.3$ & $0.117 \pm 0.019$ & - \\
\hline control poly(HPMA-co-HAO) & $117.1 \pm 0.9$ & $0.076 \pm 0.014$ & - \\
\hline
\end{tabular}

Note: The magnetization of the polymer-coated samples per weight of $\mathrm{Fe}_{2} \mathrm{O}_{3}$ was assumed to be equal to the magnetization of initial magnetic cores before coating. The saturation magnetization was determined as magnetization in a magnetic field of $\mu_{0} H=3 \mathrm{~T}$ at $300 \mathrm{~K}$

successfully indexed within the cubic space group of $F d \overline{3} m$, which is consistent with the maghemite structure with no ordering of vacancies on octahedral sites. However, considering the significant line broadening, the weak tetragonal diffraction lines characteristic for maghemite structures with vacancy ordering might have remained detected. By all means, the considerable line broadening evidenced the nanocrystalline character of the prepared samples. The lattice parameters of the anionic, cationic, and control particles were determined to be $a=8.3508$ (4) $\AA$, 8.3515(2) $\AA$, and 8.3549(5) $\AA$; i.e., the lattice constant was found in a narrow interval, indicating a similar oxygen stoichiometry of all the three samples.

\section{Mössbauer spectroscopy}

The maghemite $\left(\gamma-\mathrm{Fe}_{2} \mathrm{O}_{3}\right)$ possesses a modified spinel structure schematized by (Fe) $\left[\mathrm{Fe}_{5 / 3} \square_{1 / 3}\right] \mathrm{O}_{4}$, where ( ) denotes the tetrahedral A-sites, [ ] denotes the octahedral B-sites, and $\square$ denotes the vacancies.

The zero-field Mössbauer spectra (see Fig. 6a, c, e, g) showed an asymmetric sextet with poorly resolved lines. Its decomposition into two magnetic components, which were attributed to the tetrahedral (A) and octahedral [B] Fe sites, remained ambiguous due to low resolution, which prevented reaching high accuracy of their relative intensities.
Fig. 3 Temperature dependence of remanent magnetization, $M_{\mathrm{r}}$, of the nanoparticles (both initial cores and polymer-coated nanoparticles) measured while heating the samples originally magnetized at $5 \mathrm{~K}$. The magnetization values are normalized to the remnant magnetization at $5 \mathrm{~K}$

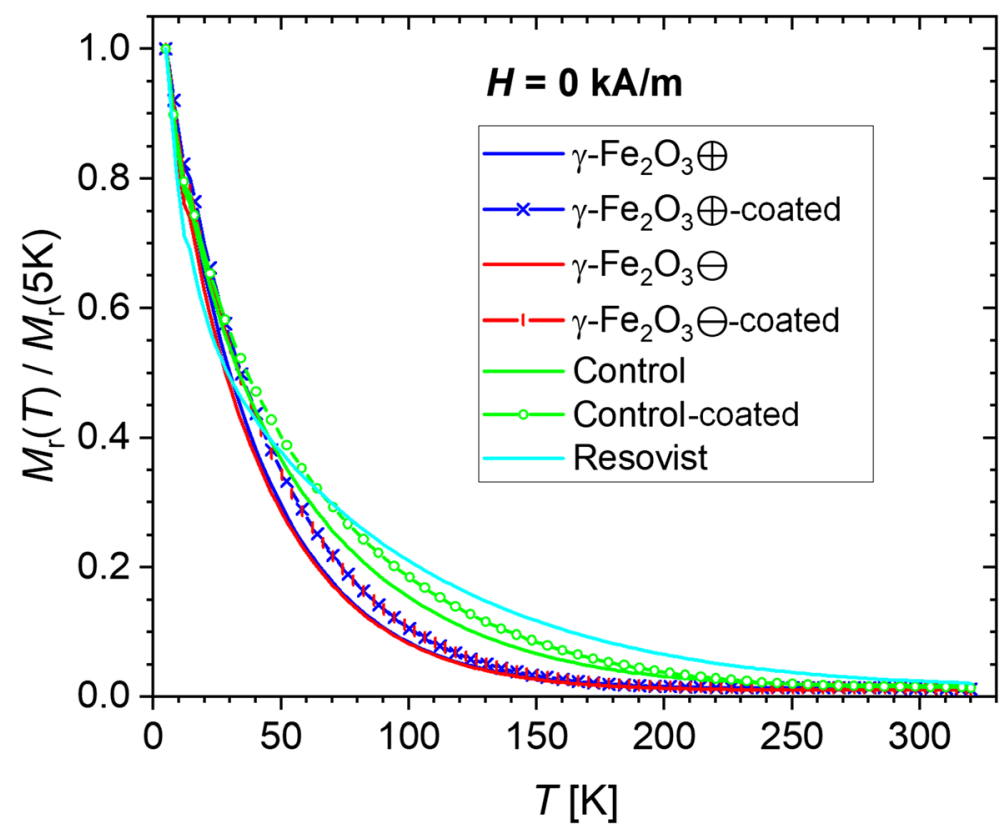


Fig. 4 ZFC/FC studies of both initial and polymer-coated particles in a magnetic field of $\mu_{0} H=2$ $\mathrm{mT}$ : a mass susceptibilities, $\chi_{\mathrm{ZFC}}$ and $\chi_{\mathrm{FC}}$, of the $\gamma-\mathrm{Fe}_{2} \mathrm{O}_{3}$ phase; $\mathbf{b}$ temperature derivative of the $\chi_{\text {ZFC }}-\chi_{\text {FC }}$ difference (a)
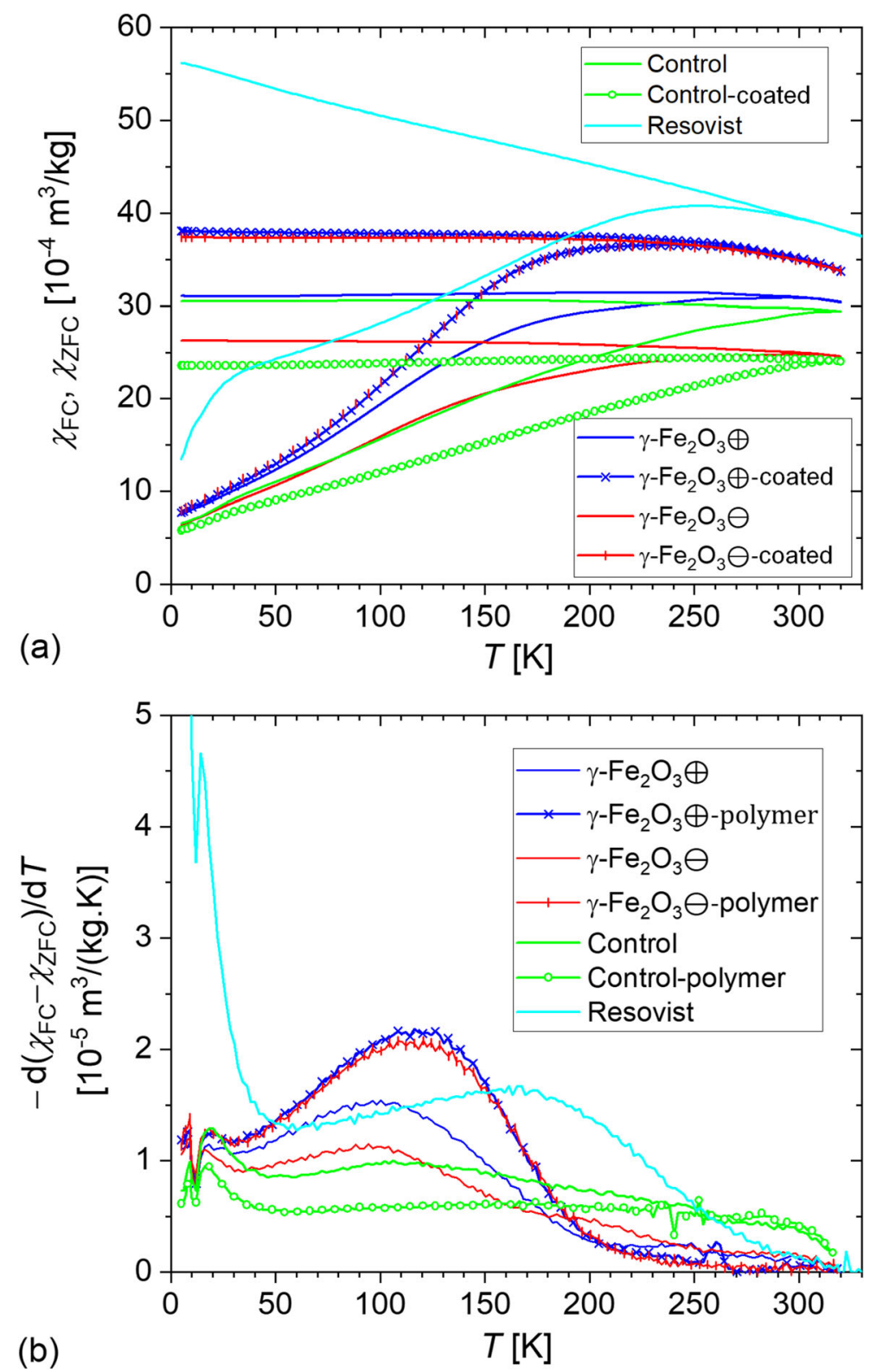

On the contrary, the application of an external magnetic field $B_{\text {ext }}=6 \mathrm{~T}$ clearly split the spectra into two well-resolved magnetic components allowing for the discrimination between spins oriented parallel to the external magnetic field and those oriented opposite to the external magnetic field following the ferrimagnetic arrangement, as can be seen in Fig. $6(\mathrm{~b}, \mathrm{~d}, \mathrm{f}, \mathrm{h})$. Large interparticle distances in frozen aqueous suspensions guaranteed that the spectra were not affected by mutual interparticle interactions.
Based on the integral intensities of spectral components attributed to iron in (A) and [B] sites (see Table 2), the distribution of iron within both sites slightly differs from the theoretical ones, $I_{\mathrm{A}}=37.5 \%$ and $I_{\mathrm{B}}=62.5 \%$, respectively. The observed isomer shifts for all samples at liquid helium temperature, $I S=0.38(3) \mathrm{mm} / \mathrm{s}$ in tetrahedral (A) and $I S=0.50(2) \mathrm{mm} / \mathrm{s}$ in octahedral [B] sites, are in good agreement with those reported in (Tronc et al. 1998) for $\mathrm{Fe}^{3+}$ cations in nanosized maghemite $\left(\gamma-\mathrm{Fe}_{2} \mathrm{O}_{3}\right)$, specifically $I S=0.36(2) \mathrm{mm} / \mathrm{s}$ 
Fig. 5 XRD patterns of bare maghemite particles prepared for the present study: nanoparticles with anionic stabilization $(\gamma$ $\mathrm{Fe}_{2} \mathrm{O}_{3}{ }^{\ominus}$ ), nanoparticles with cationic stabilization $\left(\gamma-\mathrm{Fe}_{2} \mathrm{O}_{3}{ }^{\oplus}\right)$, and control particles. The experimental patterns are complemented by calculated patterns (black lines) based on the Rietveld analysis. The vertical green markers indicate the diffraction line positions of the maghemite phase with the $F d \overline{3} m$ symmetry

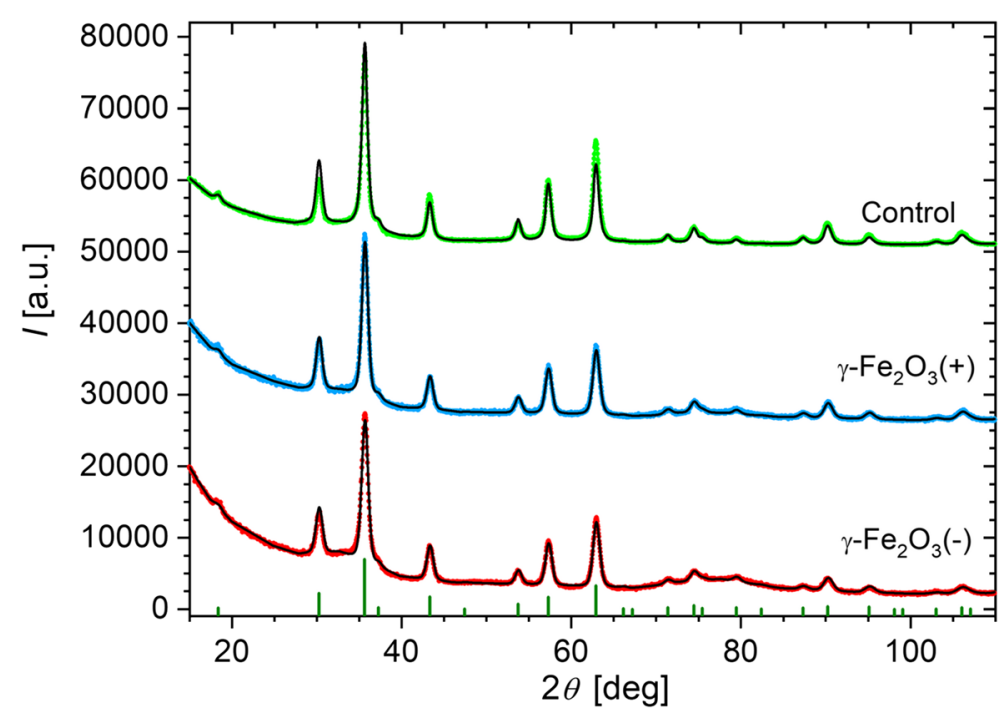

and $I S=0.47(2) \mathrm{mm} / \mathrm{s}$. Similarly, the effective magnetic field on ${ }^{57} \mathrm{Fe}$ nuclei $B_{\text {eff }}=57.4(3) \mathrm{T}$ in tetrahedral (A) and $B_{\text {eff }}=47.0(3) \mathrm{T}$ in octahedral [B] sites observed with an applied external magnetic field of $B_{\text {ext }}=6 \mathrm{~T}$ is consistent with reported value $B_{\text {eff }}=56.4-57.9 \mathrm{~T}$ and $B_{\text {eff }}=46.9-47.6 \mathrm{~T}$, respectively, in dependence on the particle sizes of maghemite (Tronc et al. 1998). Nearly zero quadrupole shift $Q S$ of both sextets corresponded to the cubic structure of maghemite.

No other $\mathrm{Fe}_{2} \mathrm{O}_{3}$ polymorphs (Kubaniova et al. 2019), namely $\alpha-\mathrm{Fe}_{2} \mathrm{O}_{3}$ (hematite), $\beta-\mathrm{Fe}_{2} \mathrm{O}_{3}, \varepsilon-\mathrm{Fe}_{2} \mathrm{O}_{3}$, or other iron-containing impurities, such as magnetite $\left(\mathrm{Fe}^{3+}\right)\left[\mathrm{Fe}^{2+} \mathrm{Fe}^{3+}\right] \mathrm{O}_{4}$ (Schwaminger et al. 2017), were detected in Mössbauer spectra within the accuracy of the measurement, which is $1-2 \mathrm{w} \%$.

In the magnetically split six-line spectra, the relative integral intensities of lines 2 and $5\left(I_{1,6}: I_{2,5}: I_{3,4}=3: b: 1\right)$ depend on the angle $\vartheta$ between the magnetic hyperfine field and the $\gamma$-ray direction through the relation $b=$ $4 \sin ^{2} \vartheta /\left(1+\cos ^{2} \vartheta\right)$.

A thorough analysis of the in-field Mössbauer spectra, shown in Fig. 6b and f, suggests that the spectra can be interpreted by means of the core-shell model (Coey 1971; Daou et al. 2010). The model assumes that the contribution of iron magnetic moments within the particles to the spectrum can be divided between randomly canted iron moments near the surface of particles (magnetic shell) and saturated iron moments fully aligned to the direction of external magnetic field (magnetic core). If we denote $I_{\mathrm{S}}$ and $I_{\mathrm{C}}$ as integral intensities corresponding to the magnetic shell and core, respectively, we can define the proportion of the shell in the particles as $f=I_{\mathrm{S}} /$ $\left(I_{\mathrm{S}}+I_{\mathrm{C}}\right)=3(4-b) /(b+4)$. For the coated and uncoated $\gamma-$ $\mathrm{Fe}_{2} \mathrm{O}_{3}{ }^{\oplus}$ particles $(\sim 8.0 \mathrm{~nm})$, and coated and uncoated $\gamma$ $\mathrm{Fe}_{2} \mathrm{O}_{3}{ }^{\ominus}$ particles $(\sim 8.7 \mathrm{~nm}), f$ is estimated to be about $\sim 2, \sim 7, \sim 7$, and $\sim 11 \%$, respectively. The relative decrease of the magnetic shell proportion of coated nanoparticles compared to their uncoated counterparts suggests that the coating polymer affects the ordering of the magnetic moments in the surface layer of particles. The magnetic shell proportion in the control sample $(6-7 \mathrm{~nm}$ (Horak et al. 2007)) and Resovist ( $4.2 \mathrm{~nm}$ (Laga et al. 2007)) was estimated to about $\sim 11 \%$ and $\sim 21 \%$, respectively, based on the data provided in Supplementary Information (see Figure S2 and Table S1).

Magnetic particle imaging

The signal-to-noise ratios and a measure of signal displacement of the tested samples are summarized in Table 3. Cationic (coated and uncoated) $\gamma-\mathrm{Fe}_{2} \mathrm{O}_{3}{ }^{\oplus}$ particles provided a signal insignificantly lower than Resovist, which was used as a standard. Uncoated anionic $\gamma-\mathrm{Fe}_{2} \mathrm{O}_{3}{ }^{\ominus}$ particles provided a slightly higher $\mathrm{S} / \mathrm{N}$, while coated ones have an $\mathrm{S} / \mathrm{N}$ identical to Resovist. A very low $\mathrm{S} / \mathrm{N}$ was found in the control sample (differently oxidized nanoparticles).

Substantial changes were observed in signal dispersion. In the case of cationic $\gamma-\mathrm{Fe}_{2} \mathrm{O}_{3}{ }^{\oplus}$ nanoparticles, dispersion to surrounding voxels (or signal dislocation) was comparable to Resovist, while anionic $\gamma-\mathrm{Fe}_{2} \mathrm{O}_{3}{ }^{\ominus}$ particles demonstrated a significantly lower signal 


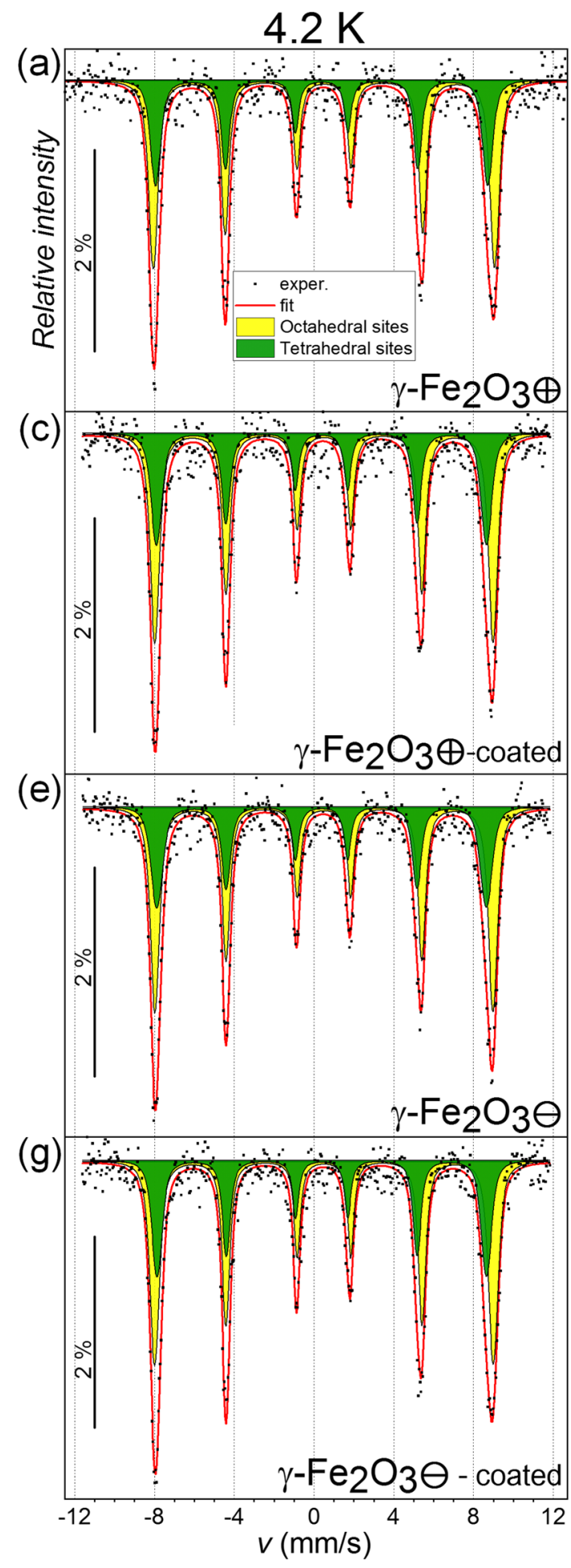

Fig. 6 The Mössbauer spectra of frozen aqueous suspensions of uncoated cationic $\gamma-\mathrm{Fe}_{2} \mathrm{O}_{3}{ }^{\oplus}(\mathbf{a}, \mathbf{b})$, uncoated anionic $\gamma-\mathrm{Fe}_{2} \mathrm{O}_{3}{ }^{\ominus}$ (e, f), poly(HPMA-co-HAO)-coated cationic $\gamma-\mathrm{Fe}_{2} \mathrm{O}_{3}{ }^{\oplus}$ (c, d), and

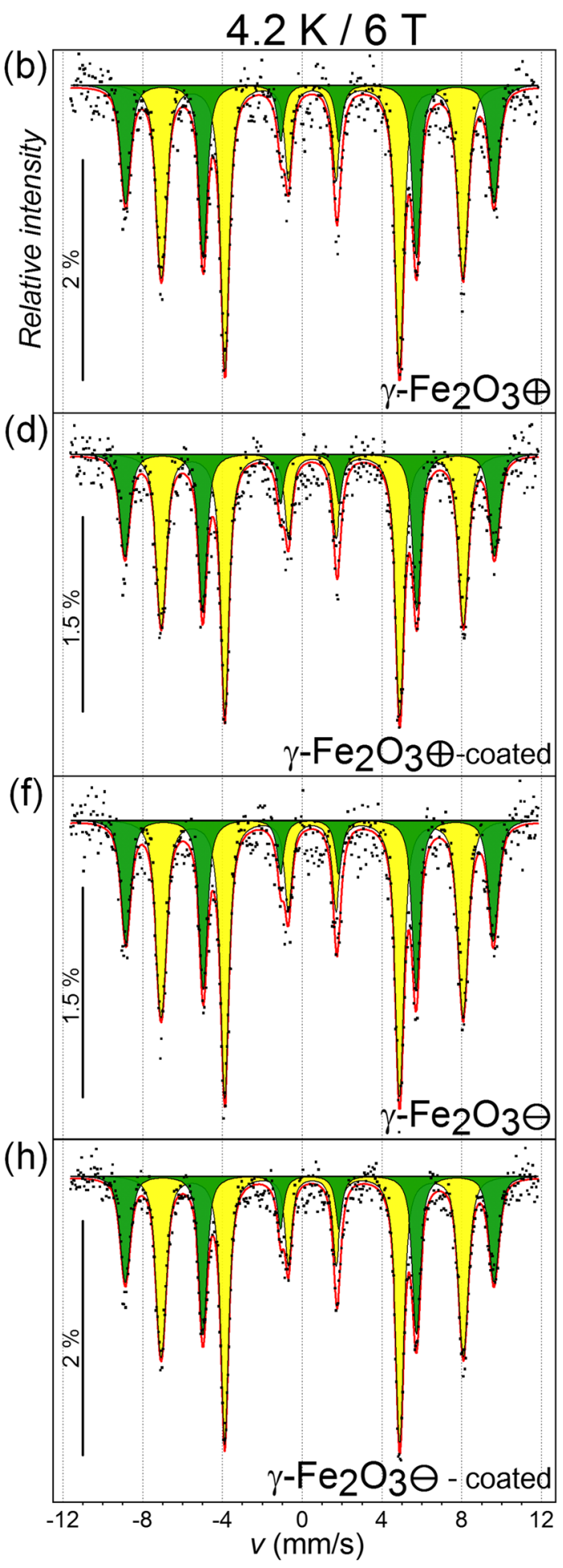

poly(HPMA-co-HAO)-coated anionic $\gamma-\mathrm{Fe}_{2} \mathrm{O}_{3}{ }^{\ominus}$ nanoparticles $(\mathbf{g}, \mathbf{h})$ acquired at liquid helium temperature $(\mathbf{a}, \mathbf{c}, \mathbf{e}, \mathbf{g})$ and in the external magnetic field $B_{\text {ext }}=6 \mathrm{~T}(\mathbf{b}, \mathbf{d}, \mathbf{f}, \mathbf{h})$ 
Table 2 The hyperfine parameters determined from the ${ }^{57} \mathrm{Fe}$ Mössbauer spectra of investigated nanoparticles - uncoated $\gamma$ $\mathrm{Fe}_{2} \mathrm{O}_{3}{ }^{\oplus}, \gamma-\mathrm{Fe}_{2} \mathrm{O}_{3}{ }^{\ominus}$, and their poly(HPMA-co-HAO)-coated derivatives - acquired at liquid helium temperature. The parameter designation: $I$, integral intensity; $B_{h f}$, hyperfine magnetic field; $B_{\text {eff }}$, effective magnetic field; $B_{\text {ext }}$, external magnetic field; $I S$, isomer shift; $Q S$, quadrupole shift; and $b=I_{2,5} / I_{3,4}$, relative intensities

\begin{tabular}{|c|c|c|c|c|c|c|c|c|}
\hline Particle & site & $B_{e x t}[\mathrm{~T}]$ & $B_{h f}[\mathrm{~T}]$ & $B_{e f f}[\mathrm{~T}]$ & $I S[\mathrm{~mm} / \mathrm{s}]$ & $Q S[\mathrm{~mm} / \mathrm{s}]$ & $I[\%]$ & $b$ \\
\hline \multirow[t]{4}{*}{$\gamma-\mathrm{Fe}_{2} \mathrm{O}_{3}{ }^{\oplus}$} & A-tetrahedral & 0 & $51.8(3)$ & - & $0.39(3)$ & $-0.07(5)$ & $37.5^{*}$ & $2.05(5)$ \\
\hline & B-octahedral & 0 & $53.1(3)$ & - & $0.50^{*}$ & $0.03(4)$ & $62.5^{*}$ & $2.05(5)$ \\
\hline & A-tetrahedral & 6 & $51.4(3)^{a}$ & $57.4(3)$ & $0.38(3)$ & $-0.02(2)$ & $37.7(7)$ & $3.82(8)$ \\
\hline & B-octahedral & 6 & $53.0(3)^{a}$ & $47.0(3)$ & $0.50(2)$ & $0.01(2)$ & $62.3(7)$ & $3.82(8)$ \\
\hline \multirow[t]{4}{*}{$\gamma-\mathrm{Fe}_{2} \mathrm{O}_{3}^{\ominus}$} & A-tetrahedral & 0 & $51.3(3)$ & - & $0.38(3)$ & $-0.01(3)$ & $37.5^{*}$ & $2.00(3)$ \\
\hline & B-octahedral & 0 & $52.7(3)$ & - & $0.50 *$ & $0.00(4)$ & $62.5^{*}$ & $2.00(3)$ \\
\hline & A-tetrahedral & 6 & $51.3(3)^{a}$ & $57.3(3)$ & $0.37(3)$ & $-0.01(2)$ & $36.2(7)$ & $3.71(8)$ \\
\hline & B-octahedral & 6 & $53.0(3)^{a}$ & $47.0(3)$ & $0.50(2)$ & $0.01(2)$ & $63.8(7)$ & $3.71(8)$ \\
\hline \multirow[t]{4}{*}{$\gamma-\mathrm{Fe}_{2} \mathrm{O}_{3}{ }^{\oplus}$ coated } & A-tetrahedral & 0 & $51.4(3)$ & - & $0.37(3)$ & $-0.02(4)$ & $37.5^{*}$ & $2.04(5)$ \\
\hline & B-octahedral & 0 & $52.7(3)$ & - & $0.50 *$ & $0.00(3)$ & $62.5^{*}$ & $2.04(5)$ \\
\hline & A-tetrahedral & 6 & $51.6(3)^{a}$ & $57.6(3)$ & $0.38(3)$ & $-0.01(3)$ & $34.9(7)$ & $3.95(9)$ \\
\hline & B-octahedral & 6 & $53.1(3)^{a}$ & $47.1(3)$ & $0.51(2)$ & $0.01(3)$ & $65.1(7)$ & $3.95(9)$ \\
\hline \multirow[t]{4}{*}{$\gamma-\mathrm{Fe}_{2} \mathrm{O}_{3}{ }^{\ominus}$ coated } & A-tetrahedral & 0 & $51.3(3)$ & - & $0.39(3)$ & $-0.04(4)$ & $37.5^{*}$ & $2.04(4)$ \\
\hline & B-octahedral & 0 & $52.7(3)$ & - & $0.50^{*}$ & $0.02(3)$ & $62.5^{*}$ & $2.04(4)$ \\
\hline & A-tetrahedral & 6 & $51.4(2)^{a}$ & $57.4(2)$ & $0.38(2)$ & $0.01(3)$ & $36.3(4)$ & $3.81(4)$ \\
\hline & B-octahedral & 6 & $53.1(2)^{a}$ & $47.1(2)$ & $0.50(2)$ & $0.00(3)$ & $63.7(4)$ & $3.81(4)$ \\
\hline
\end{tabular}

*Fixed, ${ }^{a} B_{h f}=\left(B_{\text {eff }}-B_{\text {ext }}\right)$ assuming that the magnetic moments of $\mathrm{Fe}^{3+}$ are oriented in the direction of the external magnetic field

dispersion. Signal displacement constituted a serious problem for samples containing the control iron oxide particles. A complete dislocation was observed in this case (i.e., the highest signal was localized in a voxel corresponding to an empty space).

\section{Discussion}

Nanoparticles used as a tracer in MPI have a substantial impact on the signal. The signal is affected by nanoparticle magnetization, possible hysteresis, Néel, and Brownian relaxations. These properties are closely related to the nanoparticle core size and structure (magnetization, Néel relaxation) as well as to their coating and surface interactions (Brownian relaxation). A narrow distribution of the nanoparticle sizes and the stability of the suspension are also of significance.

The presented synthesis delivered slightly larger cores with a narrow size distribution, which is advantageous for MPI. The charge of the particles together with the poly(HPMA-co-HAO) coating enhanced suspension stability. The introductions of amine, carboxylic acid, and hydroxamic acid functional groups to the structure facilitated good stability, which would be necessary for any subsequent in vivo applications in the future.

Magnetometry confirmed superior properties of both cationic and anionic particles compared to control particles and Resovist, which includes a faster Néel relaxation and narrower distribution of blocking temperatures. This is also reflected by the improved performance of the newly synthetized particles as a tracer for MPI.

The crystalline structure of the nanoparticles was studied by using conventional XRD. Differentiation of maghemite $\left(\gamma-\mathrm{Fe}_{2} \mathrm{O}_{3}\right)$ and magnetite $\left(\mathrm{Fe}_{3} \mathrm{O}_{4}\right)$ structures is difficult, as both iron oxides have the same cubic structure with nearly identical lattice parameters (Kim et al. 2012). Therefore, XRD was supplemented by Mössbauer spectroscopy, which reliably confirmed maghemite $\left(\gamma-\mathrm{Fe}_{2} \mathrm{O}_{3}\right)$ structure of the synthetized nanoparticles.

The method used for testing of MPI signal quality represents a fast and simple-albeit rather phenomenological-method for tracer evaluation. The method assessed the practical usability of the tracers, even though it lacked exact evaluation, which provided magnetometry and relaxometry. It should be noted that the fieldfree-point approach with calibration scans performed with the given tracer may tolerate (due to the fitting of the 
Table 3 Signal-to-noise ratios and signal dislocation figures of the tested samples. The value for $\mathrm{S} / \mathrm{N}$ (calculated as a ratio of the signal in the sample position to the sum of signals from all other voxels) is related to the $\mathrm{S} / \mathrm{N}$ value of Resovist (i.e., $\mathrm{S} / \mathrm{N}$ of Resovist $=100 \%$ ). Signal dislocation is expressed as a ratio (percentage) of the maximum signal outside the sample position to the signal in the

\begin{tabular}{llc}
\hline Nanoparticles & $\mathrm{S} / \mathrm{N}(\%)$ & Signal dislocation $(\%)$ \\
\hline Resovist & $100 \pm 12$ & $83 \pm 10$ \\
$\gamma-\mathrm{Fe}_{2} \mathrm{O}_{3}{ }^{\oplus}$ & $84 \pm 7$ & $75 \pm 7$ \\
$\gamma-\mathrm{Fe}_{2} \mathrm{O}_{3}^{\oplus}$ poly(HPMA-co-HAO) & $88 \pm 15$ & $66 \pm 10$ \\
$\gamma-\mathrm{Fe}_{2} \mathrm{O}_{3}{ }^{\ominus}$ & $115 \pm 19$ & $49 \pm 13$ \\
$\gamma-\mathrm{Fe}_{2} \mathrm{O}_{3}{ }^{\ominus}$ poly(HPMA-co-HAO) & $101 \pm 10$ & $48 \pm 8$ \\
$\mathrm{Control} \mathrm{uncoated}_{\text {Control poly(HPMA-co-HAO) }}$ & $29 \pm 21$ & $560 \pm 700$ \\
\end{tabular}

actual position of the sample $(100 \%$ means that a signal of the same intensity as was found in the actual sample position occurs also in another area). Average values from measurements with the sample at different positions in space are presented with standard deviations measured data by calibration data obtained from real tracer measurements) small imperfections in superparamagnetic behavior (small hysteresis, low steepness, etc.), which could otherwise produce ambiguity in MPI signal.

There were no substantial differences between coated and uncoated particles (albeit the uncoated ones might tend to aggregate). This indicates that Brownian relaxation, which might differ due to the presence of the coating, had a negligible effect on particle performance in a water colloid.

While the $\mathrm{S} / \mathrm{N}$ ratios of both cationic and anionic particles were comparable to Resovist (cationic ones had the $\mathrm{S} / \mathrm{N}$ ratio slightly lower, anionic ones moderately higher), their lower signal dispersion/dislocation makes them preferable.

The higher MPI signal dispersion of Resovist also indicates a broader nanoparticle size distribution. This finding is in agreement with ZFC/FC magnetometry. Resovist had a stronger paramagnetic component and its ZFC and FC curves converged at higher temperatures compared to the anionic particles. The temperature derivative $(\chi \mathrm{FC}-\chi \mathrm{ZFC}) / \mathrm{dT}$ revealed faster Néel relaxation of both anionic and cationic particles compared to Resovist or control particles.

Interestingly, we found substantial differences in MPI performance between anionic and cationic particles. Anionic ones had a substantially higher $\mathrm{S} / \mathrm{N}$ ratio and lower signal dispersion than cationic ones despite the supposedly identical core structure. Neither TEM nor DLS revealed any significant differences in their size or tendency to aggregate. Moreover, anionic particles had a significantly lower signal dispersion/dislocation. Magnetometry detected no substantial difference between cationic and anionic particles; therefore, the inferior performance of cationic particles relative to anionic ones remains unexplained.

Surprisingly, control particles prepared according to (Babic et al. 2008) yielded the poorest results with a low $\mathrm{S} / \mathrm{N}$ ratio, high signal dispersion to the surrounding voxels, or even complete signal dislocation. ZFC/FC magnetometry revealed a considerable paramagnetic component, broad distribution of blocking temperatures, and slow Néel relaxation, which may explain their poor MPI performance. The signal dislocation attributed to substantial hysteresis at given frequencies was probably caused by long relaxation processes. This observation disqualifies these nanoparticles as an MPI tracer, although they have been reported as a superb contrast agent for MRI (Babic et al. 2008).

\section{Conclusion}

A suitable size, narrow size distribution, and colloidal stability predispose the synthetized maghemite nanoparticles coated by poly( $N$-(2-hydroxypropyl) methacrylamide)-co- $N$-[2-(hydroxyamino)-2-oxo-ethyl]-2-methyl-prop-2-enamide for use as a tracer for MPI. The particles thus may replace the commercial products used for magnetic particle imaging especially in any applications, where further functionalization of the coating is required. The present study has also showed that suitable magnetic properties depend, to a great degree, on the preparation procedure. 
Supplementary Information The online version contains supplementary material available at https://doi.org/10.1007/s11051021-05164-x.

Author contribution VH performed MPI measurements, processed MPI data and wrote the main part of the manuscript, MB designed and synthetized nanoparticles, OK performed and interpreted magnetometry and X-ray diffraction measurements, $\mathrm{HC}$ synthetized nanoparticles, MVe and OB performed MPI measurements, MVo evaluated composition of the particles, DK performed Mössbauer experiments, JK evaluated and interpreted the Mössbauer data, UGH coordinated collaboration between Prague and Freiburg labs and critically reviewed the manuscript, L $\breve{S}$ coordinated and arranged funds for the project. All authors reviewed the manuscript.

Funding The research was supported by Czech Science Foundation - Project No. 19-02584S, Ministry of Education, Youth and Sports of the Czech Republic - Czech-BioImaging LM2018129, and National Sustainability Program II (Project BIOCEV-FAR LQ1604), German Research Ministry's project FMT 13GW0230A. The facility infrastructure was supported by European Regional Development Fund No. CZ.02.1.01/0.0/0.0/ $18 \_046 / 0016045$ (OPVVV project).

Data AvailabilityRaw data are available upon request.

Code availabilityThe code of the in-house script ISNER used for processing of the images is available upon request.

\section{Declarations}

Conflict of interest The authors declare no competing interests.

Open Access This article is licensed under a Creative Commons Attribution 4.0 International License, which permits use, sharing, adaptation, distribution and reproduction in any medium or format, as long as you give appropriate credit to the original author(s) and the source, provide a link to the Creative Commons licence, and indicate if changes were made. The images or other third party material in this article are included in the article's Creative Commons licence, unless indicated otherwise in a credit line to the material. If material is not included in the article's Creative Commons licence and your intended use is not permitted by statutory regulation or exceeds the permitted use, you will need to obtain permission directly from the copyright holder. To view a copy of this licence, visit http://creativecommons.org/licenses/by/4.0/.

\section{References}

Arbab AS, Bashaw LA, Miller BR, Jordan EK, Bulte JW, Frank JA (2003) Intracytoplasmic tagging of cells with ferumoxides and transfection agent for cellular magnetic resonance imaging after cell transplantation: methods and techniques.
Transplantation 76(7):1123-1130. https://doi.org/10.1097 /01.TP.0000089237.39220.83

Babic M, Horak D, Trchova M, Jendelova P, Glogarova K, Lesny P, Herynek V, Hajek M, Sykova E (2008) Poly(L-lysine)modified iron oxide nanoparticles for stem cell labeling. Bioconjug Chem 19(3):740-750. https://doi.org/10.1021 /bc700410z

Babic M, Horak D, Jendelova P, Glogarova K, Herynek V, Trchova M, Likavanova K, Lesny P, Pollert E, Hajek M, Sykova E (2009) Poly(N,N-dimethylacrylamide)-coated maghemite nanoparticles for stem cell labeling. Bioconjug Chem 20(2):283-294

Bulte JWM (2019) Superparamagnetic iron oxides as MPI tracers: A primer and review of early applications. Adv Drug Deliv Rev 138:293-301. https://doi.org/10.1016/j. addr.2018.12.007

Coey JMD (1971) Noncollinear Spin Arrangement in Ultrafine Ferrimagnetic Crystallites. Phys Rev Lett 27(17):1140-1142. https://doi.org/10.1103/PhysRevLett.27.1140

Croft LR, Goodwill PW, Konkle JJ, Arami H, Price DA, Li AX, Saritas EU, Conolly SM (2016) Low drive field amplitude for improved image resolution in magnetic particle imaging. Med Phys 43(1):424. https://doi.org/10.1118/1.4938097

Daou TJ, Greneche JM, Lee SJ, Lee S, Lefevre C, Begin-Colin S, Pourroy G (2010) Spin Canting of Maghemite Studied by NMR and In-Field Mossbauer Spectrometry. J Phys Chem C 114(19):8794-8799. https://doi.org/10.1021/jp100726c

Ferguson RM, Minard KR, Krishnan KM (2009) Optimization of nanoparticle core size for magnetic particle imaging. J Magn Magn Mater 321(10):1548-1551. https://doi.org/10.1016/j. jmmm.2009.02.083

Gleich B, Weizenecker R (2005) Tomographic imaging using the nonlinear response of magnetic particles. Nature 435(7046): 1214-1217. https://doi.org/10.1038/nature03808

Goodwill PW, Conolly SM (2010) The X-space formulation of the magnetic particle imaging process: 1-D signal, resolution, bandwidth, SNR, SAR, and magnetostimulation. IEEE Trans Med Imaging 29(11):1851-1859. https://doi. org/10.1109/TMI.2010.2052284

Herynek V, Babič M, Kaman O, Charvátová H, Veselá M, Šefc L (2020) Development of novel nanoparticles for MPI. Int J Mag Part Imag 6(2):2009019. https://doi.org/10.18416 /IJMPI.2020.2009019

Horak D, Babic M, Jendelova P, Herynek V, Trchova M, Pientka Z, Pollert E, Hajek M, Sykova E (2007) D-Mannosemodified iron oxide nanoparticles for stem cell labeling. Bioconjug Chem 18(3):635-644. https://doi.org/10.1021 /bc060186c

Kalish H, Arbab AS, Miller BR, Lewis BK, Zywicke HA, Bulte JW, Bryant LH Jr, Frank JA (2003) Combination of transfection agents and magnetic resonance contrast agents for cellular imaging: relationship between relaxivities, electrostatic forces, and chemical composition. Magn Reson Med 50(2):275-282. https://doi.org/10.1002/mrm.10556

Kawaguchi T, Hanaichi T, Hasegawa M, Maruno S (2001) Dextran-magnetite complex: conformation of dextran chains and stability of solution. J Mater Sci Mater Med 12(2):121127

Kim W, Suh CY, Cho SW, Roh KM, Kwon H, Song K, Shon IJ (2012) A new method for the identification and quantification of magnetite-maghemite mixture using conventional X- 
ray diffraction technique. Talanta 94:348-352. https://doi. org/10.1016/j.talanta.2012.03.001

Kubaniova D, Brazda P, Zaveta K, Kmjec T, Klementova M, Kohout J (2019) Identification of ferric oxide polymorphs in nanoparticles prepared by sol-gel method and maximization of epsilon- $\mathrm{Fe}_{2} \mathrm{O}_{3}$ content. J Magn Magn Mater 472:96103. https://doi.org/10.1016/j.jmmm.2018.09.107

Laga R, Konak C, Subr V, Ulbrich K (2007) Coating of nanoparticles bearing amino groups on the surface with hydrophilic HPMA-based polymers. Colloid Polym Sci 285(13):15091514. https://doi.org/10.1007/s00396-007-1719-4

Laga R, Carlisle R, Tangney M, Ulbrich K, Seymour LW (2012) Polymer coatings for delivery of nucleic acid therapeutics. J Control Release 161(2):537-553. https://doi.org/10.1016/j. jconrel.2012.02.013

Lopez RG, Pineda MG, Hurtado G, Leon RD, Fernandez S, Saade H, Bueno D (2013) Chitosan-coated magnetic nanoparticles prepared in one step by reverse microemulsion precipitation. Int J Mol Sci 14(10):19636-19650. https://doi.org/10.3390 /ijms 141019636

Novotna B, Jendelova P, Kapcalova M, Rossner P Jr, Turnovcova K, Bagryantseva Y, Babic M, Horak D, Sykova E (2012) Oxidative damage to biological macromolecules in human bone marrow mesenchymal stromal cells labeled with various types of iron oxide nanoparticles. Toxicol Lett 210(1): 53-63. https://doi.org/10.1016/j.toxlet.2012.01.008

Reimer P, Balzer T (2003) Ferucarbotran (Resovist): a new clinically approved RES-specific contrast agent for contrastenhanced MRI of the liver: properties, clinical development, and applications. Eur Radiol 13(6):1266-1276. https://doi. org $/ 10.1007 / \mathrm{s} 00330-002-1721-7$

Schneider CA, Rasband WS, Eliceiri KW (2012) NIH Image to ImageJ: 25 years of image analysis. Nat Methods 9(7):671675. https://doi.org/10.1038/nmeth.2089

Schwaminger SP, Bauer D, Fraga-Garcia P, Wagner FE, Berensmeier S (2017) Oxidation of magnetite nanoparticles: impact on surface and crystal properties. Crystengcomm 19(2):246-255. https://doi.org/10.1039/c6ce02421a

Spitzer JJ (1992) Theory of Dissociative Electrical Double-Layers - the Limit of Close Separations and Hydration Forces. Langmuir 8(6):1659-1662. https://doi.org/10.1021/la00042 a027

Spitzer JJ (2003a) Colloidal interactions: contact limiting laws, double-layer dissociation, and "non-DLVO" (DerjaguinLandau-Verwey-Overbeek) forces. Colloid Polym Sci 281(6):589-592. https://doi.org/10.1007/s00396-002-08363
Spitzer JJ (2003b) Maxwellian double layer forces: From infinity to contact. Langmuir 19(17):7099-7111. https://doi. org/10.1021/la034028a

Spitzer JJ, Midgley CA, Slooten HSG, Lok KP (1989) On a possible relationship between stability ratios and electrophoretic mobilities of polymer lattices. Colloids Surf 39(4):273279. https://doi.org/10.1016/0166-6622(89)80278-1

Subr V, Konak C, Laga R, Ulbrich K (2006) Coating of DNA/ poly(L-lysine) complexes by covalent attachment of poly[ $\mathrm{N}$ (2-hydroxypropyl)methacrylamide]. Biomacromolecules 7(1):122-130. https://doi.org/10.1021/bm050524x

Tronc E, Prene P, Jolivet JP, Dormann JL, Greneche JM (1998) Spin canting in gamma-Fe2O3 nanoparticles. Hyperfine Interact 112(1-4):97-100. https://doi.org/10.1023 /A:1011092712136

Vallabani NVS, Singh S (2018) Recent advances and future prospects of iron oxide nanoparticles in biomedicine and diagnostics. 3. Biotech 8(6):279. https://doi.org/10.1007 /s13205-018-1286-z

Wang YX (2011) Superparamagnetic iron oxide based MRI contrast agents: Current status of clinical application. Quant Imaging Med Surg 1(1):35-40. https://doi.org/10.3978/j. issn.2223-4292.2011.08.03

Weizenecker J, Borgert J, Gleich B (2007) A simulation study on the resolution and sensitivity of magnetic particle imaging. Phys Med Biol 52(21):6363-6374. https://doi.org/10.1088 /0031-9155/52/21/001

Yang CY, Tai MF, Lin CP, Lu CW, Wang JL, Hsiao JK, Liu HM (2011) Mechanism of cellular uptake and impact of ferucarbotran on macrophage physiology. PLoS One 6(9): e25524. https://doi.org/10.1371/journal.pone.0025524

Žák T, Jirásková Y (2006) CONFIT: Mössbauer spectra fitting program. Surf Interface Anal 38(4):710-714. https://doi. org/10.1002/sia.2285

Zhang Y, Zhang J (2005) Surface modification of monodisperse magnetite nanoparticles for improved intracellular uptake to breast cancer cells. J Colloid Interface Sci 283(2):352-357. https://doi.org/10.1016/j.jcis.2004.09.042

Zhu N, Ji H, Yu P, Niu J, Farooq MU, Akram MW, Udego IO, Li H, Niu X (2018) Surface Modification of Magnetic Iron Oxide Nanoparticles. Nanomaterials (Basel) 8(10). https://doi.org/10.3390/nano8100810

Publisher's note Springer Nature remains neutral with regard to jurisdictional claims in published maps and institutional affiliations. 